International Journal of Engineering \& Technology, $7(3.20)(2018) 377-380$
International Journal of Engineering \& Technology
SPC
Website: www.sciencepubco.com/index.php/IJET
Research paper

\title{
Discrete-Event Simulation of Road Traffic Congestion to Support Green Supply Chain
}

\author{
Muhammad Zulqarnain Hakim Abd Jalal, Wan Laailatul Hanim Mat Desa, Mohd Kamal Mohd Nawawi and \\ Ruzelan Khalid
}

School of Quantitative Sciences, Universiti Utara Malaysia, 06010 UUM Sintok, Kedah, Malaysia

Corresponding Author Email: zulqarnainhakim@gmail.com

\begin{abstract}
This paper presents a discrete-event simulation (DES) study on road traffic intersections at one of the fastest developing towns in Kedah, Malaysia. Inefficient traffic light control (TLC) of the existing system contributes to the road traffic congestion (RTC) especially during peak hours, which leads to environment pollution. With the increasing awareness about environmental issues, businesses and governments increasingly want to reduce the pollution which leads to green supply chain. RTC can be caused by a temporary obstruction or a permanent capacity bottleneck in the network itself. A DES model was developed based on current system and then "what-if" scenario was analyzed to check whether improvement would be achieved. Results from the analysis show that average waiting time and number in queue could be reduced specifically at two of the lanes under study.
\end{abstract}

Keywords: Discrete-event simulation, road traffic congestion, green supply chain.

\section{Introduction}

Discrete-event simulation (DES) is widely used to imitate the behavior of real-world systems through computer modeling with appropriate software. According to [3], simulation modeling is considered as one of the most popular operational research techniques. The applications of DES cover both manufacturing and service sectors such as production line [1], port management [5], pedestrian study [4], and healthcare [6]. Amongst the output performance measures of interest to decision makers that can be collected with DES are total production, average waiting time in queue, average time in the system, average number of entities in queue, and resource utilization.

In this study, we developed a DES model for a traffic light system at one of the fastest growing town in Kedah, Malaysia, that is Changlun. It is located on North-South Expressway, the main highway in Malaysia which connects Kuala Lumpur to other destinations in mainland Asia. Weak and inefficient traffic light control (TLC) of the existing system contributes to the road traffic congestion (RTC) especially during peak hours. With high waiting time and high number of vehicles waiting at these hours, RTC will bring harms to surroundings and pollute the environment. To support the idea of green supply chain, TLC of the current system need to be studied and analyzed with the purpose of reducing average waiting time and number of vehicles waiting.

\section{Materials and Methods}

All of the authors are familiar with the existing TLC system. One of us visited the site to collect the data and observe the behavior of the system. It is a crucial part to identify the problems related in the study or otherwise there is nothing to be studied for. As for this study, the problem encountered is the RTC which occurs at Changlun main road due to ineffective management of TLC. The layout of Changlun main road is shown in Fig. 1. Current TLC timing configuration is not efficient which cause periodically bottleneck at one of the junction i.e. junction 4. As the consequences from the arising problem, the rest of the junctions at the first intersection cannot proceed to depart even when the signal shows green light. Thus, the accumulated waiting vehicles lead to a long queue and influence the waiting time.

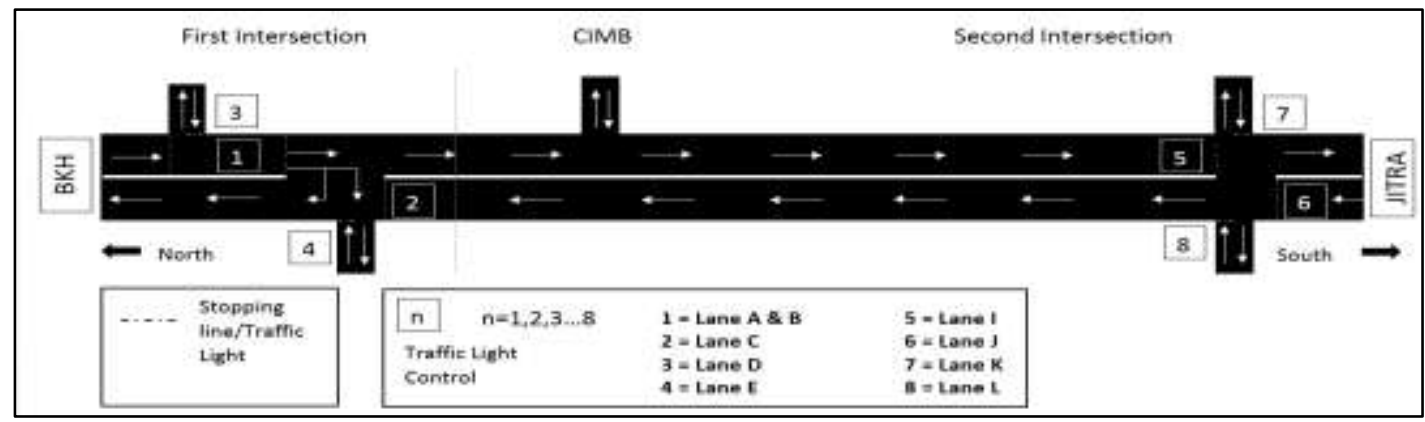

Fig. 1: The layout of Changlun main road (adopted from [2]).

Copyright $\odot 2018$ Authors. This is an open access article distributed under the Creative Commons Attribution License, which permits unrestricted use, distribution, and reproduction in any medium, provided the original work is properly cited. 
Between the red signals light to the green signal light, there is no inter-signal. However, between the green signal light and the red signal light, there will be the yellow signal light appearing as a warning light and all vehicles should take precaution to stop at all cost or clear to go if safe. When the TLC turns yellow, the vehicles are allowed to go and will only stop completely when TLC shows red signal light. The time taken, which is the measurement used to record the time cycle for TLC only starts as soon as the TLC turns green and ends only when red signal light is given. For example, while the green light duration for TLC lane A is 117 seconds, added with another 3 seconds from yellow light, the total green light duration is assumed to be 120 seconds.

After the problems have been identified, the next step is to set the objectives for the study. The main objective is to develop a simulation model that represents the road traffic at Changlun main road. Then, from the model itself, the specific TLC that causing the RTC to occur would be identified. After that, the next objective is to conduct different scenarios of TLC timing configuration using what-if analysis with the intention of proposing a better TLC timing configuration to reduce RTC. Arena software is used to develop the simulation model.

Developing a simulation model requires particular input data such as arrival rates and service times. As for this study, the interarrival time between vehicles at specific junctions were collected and analyzed using Input Analyzer, a build-in function in Arena. Input analyzer provides a probabilistic expression which will then be used in developing the model. Fig. 2 shows an example of the output obtained from input analyzer for arrival rate at junction 1 of the first intersection. Note that for junction 2 , there is no data collected as the arrival rate depends upon vehicles arrival from second intersection.

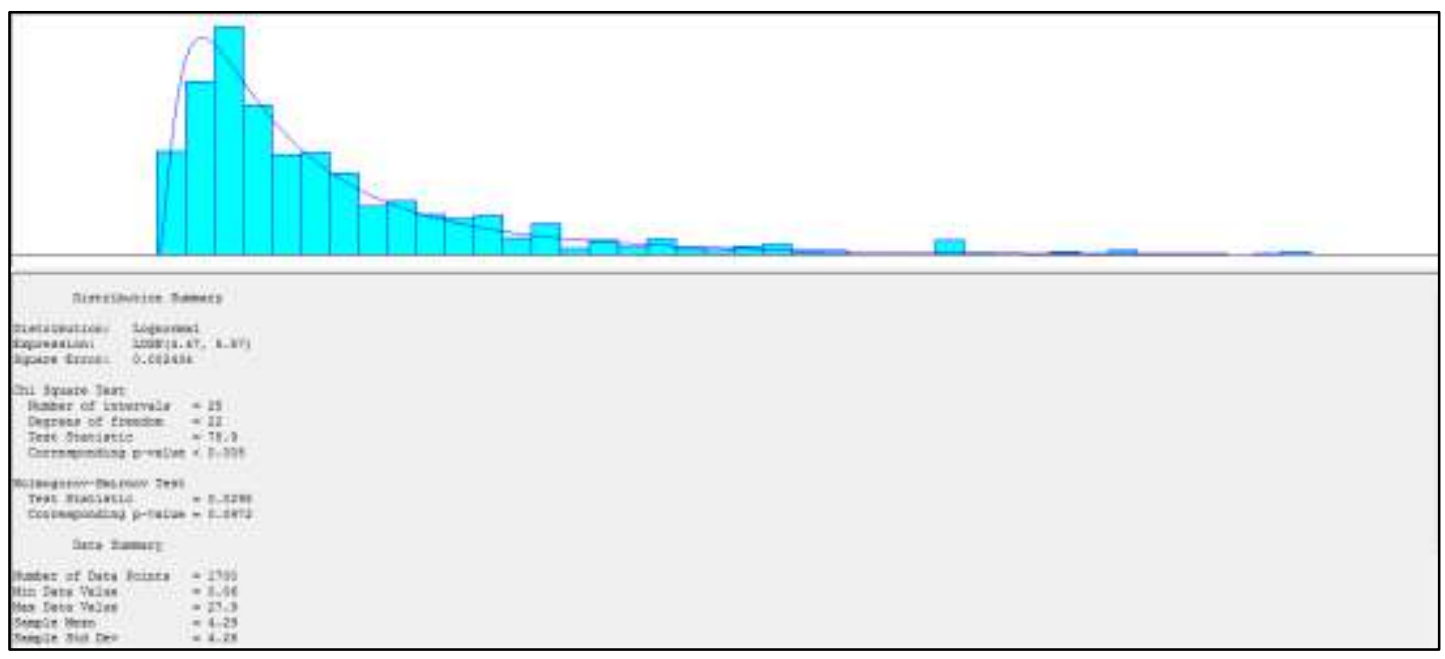

Fig. 2: Output from input analyzer for junction 1 arrival

Fig. 3 shows an example of the modeling for junction 1 using Arena flowchart module. Vehicle arrival for junction 1 was created by a create module "Junction 1 arrival". The input data for create module was taken from the expression generated by Input Analyzer. Notice that there was also another module "Bypass lane
A". From data collected, the amount of vehicles that took an exit to junction 3 and being interfered by queue from junction 1was too small. Plus, there was unintentionally widen-off road which often being used by road users to make the exit to junction 3. For that, there was separated arrival for bypass to junction 3 .

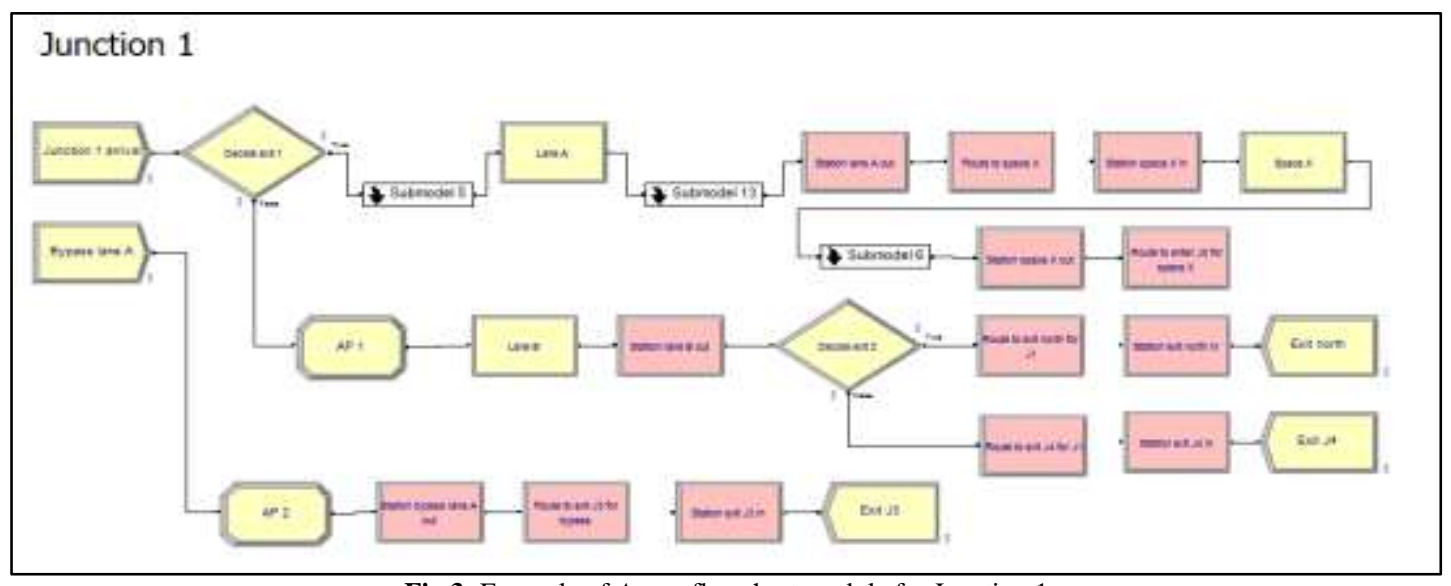

Fig 3: Example of Arena flowchart module for Junction 1

\section{Results}

\subsection{Output of Existing System}

The duration for simulation run was set for two hours regarding the period of peak hours at Changlun main road. The statistics and the system was initialized between replications, means at the beginning of each replication run, all the values are back to fresh start. Having run the model for eight replications with ten minutes of warm-up period, the average waiting time and average number of vehicle in queue for all involved junctions were obtained from the output. The warm-up period was set for ten minutes to let the system achieve steady state for traffic condition. Tables 1 and 2 show the output obtained. 
Table 1: Average waiting time for initial model

\begin{tabular}{|c|c|c|c|c|c|c|c|c|c|}
\hline & \multicolumn{9}{|c|}{ Average waiting time (s) } \\
\hline Replication & 1 & 2 & 3 & 4 & 5 & 6 & 7 & 8 & Average \\
\hline Lane A & 50.33 & 41.58 & 53.96 & 25.85 & 43.64 & 50.60 & 65.30 & 48.24 & 47.43725 \\
\hline Lane B & 71.85 & 82.874 & 75.329 & 72.443 & 85.413 & 72.133 & 84.407 & 92.37 & 79.60225 \\
\hline Lane D & 213.31 & 150.92 & 175.35 & 130.00 & 165.26 & 187.36 & 170.12 & 181.23 & 171.6938 \\
\hline Lane D Sub & 212.41 & 221.62 & 139.11 & 128.69 & 213.96 & 162.38 & 163.41 & 187.03 & 178.5763 \\
\hline Lane E & 257.8 & 333.72 & 586.31 & 117.46 & 430.1 & 251.85 & 540.25 & 359.17 & 359.5825 \\
\hline
\end{tabular}

Table 2: Average number in queue for initial model

\begin{tabular}{|c|c|c|c|c|c|c|c|c|c|}
\hline & \multicolumn{9}{|c|}{ Average number in queue } \\
\hline Replication & 1 & 2 & 3 & 4 & 5 & 6 & 7 & 8 & Average \\
\hline Lane A & 11 & 9 & 11 & 5 & 9 & 10 & 13 & 10 & 10 \\
\hline Lane B & 2 & 2 & 2 & 2 & 2 & 2 & 2 & 2 & 2 \\
\hline Lane C & 4 & 4 & 3 & 4 & 3 & 3 & 3 & 3 & 3 \\
\hline Lane D & 6 & 4 & 4 & 3 & 5 & 5 & 4 & 5 & 5 \\
\hline Lane D Sub & 7 & 7 & 4 & 3 & 6 & 4 & 4 & 5 & 5 \\
\hline Lane E & 19 & 23 & 41 & 8 & 31 & 17 & 38 & 25 & 25 \\
\hline
\end{tabular}

\subsection{Model Experimentation}

The experiment was designed by eliminating the barrier from junction 1 as circled in Fig. 4. Removing the barrier means vehicle from lane $B$ and lane $D$ sub can proceed to respective exit points without having to travel for the extra distance. Seems there was no more space which often occupied with stuck vehicle from lane A, the movement for vehicle from lane D sub was also expected to be smoothed without getting interfered. By doing this, the road traffic flows at first intersection are expected to be improved. Using the same setup for simulation run as the initial run, the result obtained are as in Tables 3 and 4.

Table 3: Average waiting time for Experiment Model

\begin{tabular}{|c|c|c|c|c|c|c|c|c|c|}
\hline \multirow[b]{2}{*}{ Replication } & \multicolumn{9}{|c|}{ Average waiting time (s) } \\
\hline & 1 & 2 & 3 & 4 & 5 & 6 & 7 & 8 & Average \\
\hline Lane A & 40.84 & 79.079 & 45.65 & 46.604 & 28.979 & 50.096 & 55.642 & 72.251 & 52.39263 \\
\hline Lane B & 78.596 & 86.014 & 74.367 & 81.246 & 79.113 & 77.062 & 87.72 & 74.543 & 79.83263 \\
\hline Lane C & 23.294 & 24.659 & 22.31 & 23.239 & 23.52 & 22.602 & 24.239 & 22.572 & 23.30438 \\
\hline Lane D & 138.5 & 220.91 & 167.71 & 148.13 & 105.97 & 155.83 & 157.45 & 162.46 & 157.12 \\
\hline Lane D Sub & 65.779 & 72.43 & 70.835 & 81.95 & 78.712 & 66.487 & 70.16 & 70.405 & 72.09475 \\
\hline Lane E & 239.87 & 713.52 & 351.77 & 159.09 & 137.56 & 230.94 & 518.53 & 454.05 & 350.6663 \\
\hline
\end{tabular}

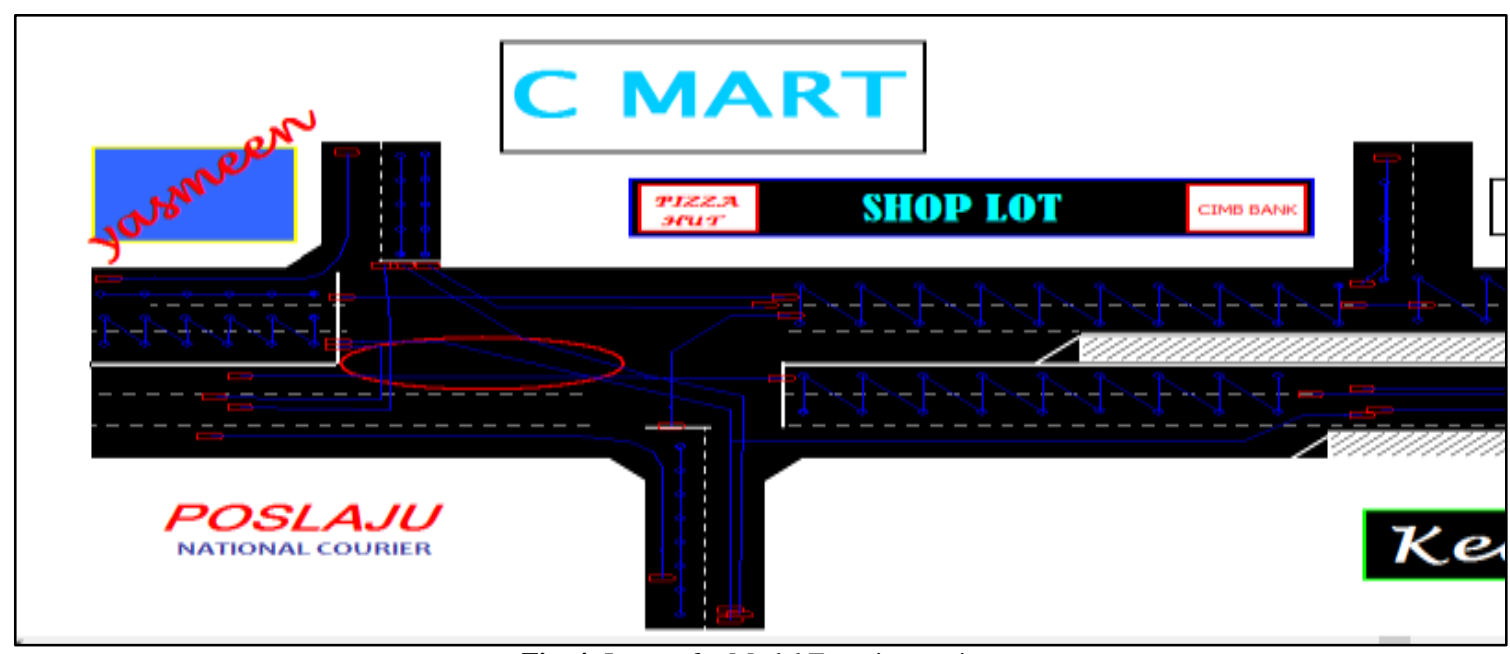

Fig. 4: Layout for Model Experimentation.

Table4:

\begin{tabular}{|c|c|c|c|c|c|c|c|c|c|}
\hline & \multicolumn{9}{|c|}{ Average number in queue } \\
\hline Replication & 1 & 2 & 3 & 4 & 5 & 6 & 7 & 8 & Average \\
\hline Lane A & 8 & 17 & 9 & 9 & 6 & 10 & 11 & 15 & 10.625 \\
\hline Lane C & 3 & 4 & 3 & 3 & 3 & 3 & 4 & 3 & 3.25 \\
\hline Lane D & 4 & 5 & 4 & 4 & 3 & 4 & 4 & 4 & 4 \\
\hline Lane D Sub & 2 & 2 & 2 & 2 & 2 & 2 & 2 & 2 & 2 \\
\hline Lane E & 18 & 49 & 26 & 11 & 9 & 16 & 39 & 35 & 25.375 \\
\hline
\end{tabular}

In comparison between initial model and experiment model,

there are not much improvement for average waiting time and 
average number in queue except for lanes D and D sub. For lane $\mathrm{D}$, average of 8 replications for average waiting time reduces from $171.69 s$ to $157.12 s$ and for average number in queue reduces from 5 to 4 . On the other hand for lane D sub which gives more significant reductions, average waiting time reduces from $178.58 s$ to $72.09 s$ and for average number in queue reduces from 5 to 2

\section{Discussion}

This paper discusses the application of discrete-event simulation to model, simulate, and analyze a traffic congestion system. A simulation model has been developed to represent the current system. Then, an experiment by modifying the layout of the traffic light intersection has been modeled to see and analyze the "what-if" output should there is an improvement from the current system. The experiment found to be an improvement model which will reduce the average waiting time and number in queue for lanes D and D sub. However, further "what-if analysis" or experimentation should be done to improve the traffic congestion such as modifying the green and red light duration for certain junctions.

In summary, the developed simulation model would be useful tool to policy and decision makers of town planning especially in developing a new or modifying an existing road traffic system. Any changes for investigation purposes can be tested on the simulation model without modifying the real operations.

\section{Acknowledgments}

This research is funded by Universiti Utara Malaysia under Geran Penjanaan with S/O Code 13411.

\section{References}

[1] Desa, W L H Mat, S Kamaruddin, M K M Nawawi, and J Zulkepli. 2015. "Evaluation on Absenteeism Effect in Production Line at Aircraft Composite Manufacturer.” Jurnal Teknologi 77(5)

[2] Jalal, M Z H A et al. 2017. "Green Supply Chain: Simulating Road Traffic Congestion." Journal of Physics: Conference Series $\quad 890$ : 12111 . http://stacks.iop.org/1742$6596 / 890 / \mathrm{i}=1 / \mathrm{a}=012111$ ?key=crossref.89e959f9f7c65855470afb 6 ed5119ca5.

[3] Kelton, D. W., R. P. Sadowski, and N. B. Zupick. 2015. Simulation with Arena. 6th ed. New York: McGraw-Hill.

[4] Khalid, R, M. A Baten, M K M Nawawi, and N Ishak. 2016. "Analyzing and Optimizing Pedestrian Flow through a Topological Network Based on M / G / C / C and Network Flow Approaches." Journal of Advanced Transportation 50(1): 96119. http://doi.wiley.com/10.1002/atr.1330 (March 23, 2016).

[5] Nawawi, M K M, F C Jamil, and F M Hamzah. 2015. "Evaluating Performance of Container Terminal Operation Using Simulation." AIP Conference Proceedings 1660(1). http://scitation.aip.org/content/aip/proceeding/aipcp/10.1063/1.4 926640.

[6] Sharif, N A M, A Aziz, N Ahmad, and M K M Nawawi. 2016. "Modelling an Outpatient Unit in a Clinical Health Centre Using Discrete Event Simulation." AIP Conference Proceedings 1782(1): 40018. http://aip.scitation.org/doi/abs/10.1063/1.4966085. 